\title{
El modelo de la espiral armónica de sor Juana: entre el pitagorismo y la modernidad
}

\author{
Rocío Olivares Zorrilla
}

\begin{abstract}
Resumen: El universo vivo del Renacimiento, con todo su legado de la Antigüedad y de la Edad Media, tuvo una expresión novohispana en las postrimerías de su extensión barroca: sor Juana Inés de la Cruz. En este trabajo se ensayará una semblanza del magisterio de Marsilio Ficino sobre la concepción universal simpática y pneumática de sor Juana, sus sentidos ocultos y las resonancias en su obra de otros ingenios de los siglos xv al XVII, que no fueron sólo poetas, filósofos o teólogos, sino también músicos y compositores. Si bien gozamos ya de excelentes estudios sobre este aspecto musical de sor Juana, todavía hay zonas inexploradas de la relación filosófica y espiritual que sor Juana estableció con el arte musical. Además de pasajes no comentados en relación con ella de Pietro Cerone, exploraré también sus paralelos con Franchino Gaffurio y Bartolomé Ramos Pareja.
\end{abstract}

Aвstract: The living universe of Renaissance, with its legacy from the Antiquity and the Middle Ages, had an Early Mexican expression in the late Renaissance or Baroque period: sor Juana Inés de la Cruz. In this paper I will essay an account of Marsilio Ficino's teachings on sor Juana's concept of a sympathetic and pneumatic universe, and of the hidden meanings and echoes in her writings from other accomplished creators from the $15^{\text {th }}$ to the $17^{\text {th }}$ centuries who were not only poets, philosophers or theologians, but also musicians and composers. Although we have already been able to read excellent essays on the musical features in sor Juana's work, there are still uninvestigated areas concerning the philosophical and spiritual relationship that she established with the musical art. Besides commenting overlooked passages by Pietro Cerone which are relevant regarding sor Juana, I will also explore the parallels between her and Franchino Gaffurio and Bartolomé Ramos Pareja.

Palabras Clave: Sor Juana Inés de la Cruz; música; armonía; pitagorismo; universo; pneuma; Jámblico; Ficino; Ramos Pareja; Gaffurio; Francisco Salinas; Cerone; temperamentos.

KeYwords: Sor Juana Inés de la Cruz; music; harmony; pythagorism; universe, pneuma; Iamblichus; Ficino; Ramos Pareja; Gaffurio; Francisco Salinas; Cerone, temperaments.

FECHA DE RECEPCIÓN: 24 de junio de 2014 FECHA DE ACEPTACIÓN: 12 de septiembre de 2014 



\title{
El modelo de la espiral armónica de sor Juana: entre el pitagorismo y la modernidad
}

\author{
Rocío Olivares Zorrilla \\ Facultad de Filosofía y Letras, UnAM \\ rocio52@prodigy.net.mx
}

El trasfondo musical de la obra de sor Juana Inés de la Cruz ha recibido la atención de connotados críticos, tanto del ámbito de la música como del de las letras. Quien parece haber inaugurado en toda forma esta veta crítica es Alfonso Méndez Plancarte en su admirable anotación de la obra de sor Juana, ${ }^{1}$ en la cual sus notas al romance 21 , a la loa 384, el Encomiástico poema a la condesa de Galve, y a la Respuesta a Sor Filotea, concentran un fiel esbozo de la teoría musical de sor Juana que ha seguido consolidándose en críticos posteriores. Una década después, Manuel Corripio Rivero contribuye con una serie de cuatro eruditos artículos publicados entre 1962 y 1964 por la revista Ábside, dirigida por los hermanos Méndez Plancarte. En ellos Corripio Rivero atribuye de manera decidida al tratadista barroco Pietro Cerone y su libro $E l$ Melopeo y maestro, ${ }^{2}$ de 1613 , el fundamento de las ideas musicales de sor Juana. Desde luego, estos trabajos despertaron el interés de otros asiduos de la obra de la novohispana. En 1980, Raymundo Lida publica su ensayo "Sor Juana y el regateo de Abraham", ${ }^{3}$ relativo a un célebre pasaje de la Respuesta donde sor Juana atribuye una significación musical a la serie de números con los que Abraham ruega a Dios el perdón de los justos que habitan en las ciudades condenadas, Sodoma y Gomorra. Podríamos afirmar que aquí nace uno de los enigmas que

${ }^{1}$ Cruz 1976: vol. I, 387-389; vol. III, 717-725; vol. IV, 649-651.

${ }^{2}$ Ver bibliografía.

${ }^{3}$ El fragmento (Cruz: vol. IV, 448-449, líneas 354-367), reza: "Pues sin ser muy perito en la Música, ¿̨cómo se entenderán aquellas proporciones musicales y sus primores que hay en tantos lugares, especialmente en aquellas peticiones que hizo a Dios Abraham, por las Ciudades, de que si perdonaría habiendo cincuenta justos, y de este número bajó a cuarenta y cinco, que es sesquinona y es como de mi a re; de aquí a cuarenta, que es sesquioctava y es como de re a mi; de aquí a treinta, que es sesquitercia, que es la del diatesarón; de aquí a veinte, que es la proporción sesquiáltera, que es la del diapente; de aquí a diez, que es la dupla, que es el diapasón; y como no hay más proporciones armónicas no pasó de ahí? Pues ¿cómo se podrá entender esto sin Música?” 
ha fascinado a quienes se han adentrado en la Respuesta. Se trata de una de esas caracterizaciones o afirmaciones que suelen llenar de incógnitas a los lectores modernos: ¿en quién se inspiró sor Juana?, ¿dónde está su fuente? ¿Lo dedujo por sí misma? ¿Formula de manera paralela lo que otros ya habían dicho o descubierto? Raymundo Lida nos deja la incógnita abierta, pues sólo encuentra como precedente de este pasaje de la Respuesta la obra de un monje benedictino francés del siglo $\mathrm{XII},{ }^{4}$ de la cual con justa razón podemos pensar que era difícil, aunque no del todo imposible, que se pudiese leer directa o indirectamente en la Nueva España. Tres ańos después Mario Lavista (95-97) contribuyó en aclarar la índole pitagórica de las reflexiones musicales de sor Juana, ${ }^{5}$ y aunque consigue hacer diáfanos a los lectores los vericuetos de los intervalos y el protagonismo del diabolus in musica que ya había comentado Méndez Plancarte en sus notas a la loa $384,{ }^{6}$ todavía no teníamos una caracterización detallada de la teoría de la música a la que sor Juana se adscribe en un siglo en el que la recepción de la herencia antigua y medieval, así como su reinterpretación renacentista, abren nuevos derroteros teóricos en sus esfuerzos por ponerse a la par de las innovaciones que la práctica musical iba aportando. Así, pues, en la crítica literaria sobre una escritora como sor Juana se hizo ya muy patente, en la década de los ochenta del siglo xx, la dimensión filológica y no sólo musicológica de la cuestión musical en su obra. Descubrir las posibles fuentes de los conocimientos de nuestra poeta se convirtió, desde la edición de Méndez Plancarte y Las trampas de la fe, de Octavio Paz, ${ }^{7}$ en la corriente más importante entre quienes se ocupan de su obra, más aún que la controvertida cuestión de su biografía, pues además de rastrear la filiación de su universo escritural, va señalando la riqueza y, por

\footnotetext{
${ }^{4}$ Ruperto de Deutz (Rupertus Titinensis), De operibus Sanctae Tritinatis, 1117; ver Lida: 456.

${ }^{5}$ Ver Cruz: vol. I, 61-65 (romance 21); vol. III, 462-482 (Encomiástico poema a los años de la Exma. Sra. Condesa de Galve); vol. IV, 448-449, líneas 323-326 y 354-367.

${ }^{6}$ Ver anotaciones de Méndez Plancarte en Cruz: vol. III, 721-723 (722: "Respecto al $S i$ [cuyo nombre sólo se introdujo en el xviı, juntando las iniciales del Sancte Ioan$n e s$, se omitía en la Escala medieval porque formaba con el $F a$ un intervalo de tres tonos, llamado tritono, cuya sucesión melódica parecía dura al oído, y era evitada como 'diabolus in musica'...)". Ver también 666-7, 669 y 695.

${ }^{7} \mathrm{Paz}$ recoge las contribuciones que le preceden y las sintetiza, aunque no propone nada adicional en el terreno estrictamente musicológico, aunque sí abunda en la dimensión poética del interés musical de sor Juana.
} 
así decirlo, sinfonía de repercusiones en su semblanza del mundo. En 1990, la tesis de Pamela Long, que retomó el título del tratado perdido que sor Juana escribió, "El caracol", y se publicó como libro en 2009, nos dibuja por fin un contorno sistemático con gran parte de los paradigmas musicales de sor Juana. Entre esas dos fechas, el ensayo de Mario Ortiz, "La musa y el Melopeo", esclareció a su vez en qué consiste la "revolución" de las cenizas pitagóricas mencionada en el romance 21 y la cuestión de la "coma perdida" que afina la idea de la armonía como una espiral. Con las aportaciones de Long y Ortiz, por fin se hace más nítido el sentido de las alusiones músico-pitagóricas que impregnan los diversos escritos de esta poeta novohispana en la encrucijada del Barroco, no sólo los ya citados, sino un sinfín de versos que, sea desde letras y villancicos o desde los parlamentos de los personajes de sus autos y loas, tienden vínculos multiplicados cuya compleja red confiere una mayor consistencia para nosotros de la figura del mundo de sor Juana, sobre todo lo relativo a la música mundana o celeste y sus afinidades con el pensamiento cristiano que llega a sor Juana de los Padres de la Iglesia, de los filósofos neoplatónicos y de sus exponentes renacentistas y barrocos. Ya Karl Vossler había dicho desde 1948 que un binomio expresa los vectores esenciales de la escritura de sor Juana: la admiratio y el concentus (124). ${ }^{9}$ En efecto, mientras más desempolvamos la arqueología de sus versos reluce mayormente la coherencia admirable que ella

${ }^{8}$ Ortiz (255) cita los cuatro versos del romance 21, Cruz: vol. I, vv. 37-40: 62: "si el temple en un instrumento, / al hacerlo necesita / de hacer participación / de una coma que hay perdida". El ensayista comenta en 255-256: "sor Juana está haciendo una referencia directa al sistema de temperamento de tono medio. La fuente para justificar esta afirmación la encontramos nuevamente en El Melopeo... La coma a la que sor Juana se refiere es la que Cerone define como 'differencia que ay entre el Semitono cantable y el incantable' (1044), o sea, la distancia entre el $b$ molle y el $b$ cuadrado. El problema fundamental de la afinación pitagórica consiste en que si afinamos cabalmente por quintas puras, la octava resultante excedería en su proporción natural por la distancia de una coma, la cual es llamada 'coma pitagórica'. Esa es la 'coma perdida' a la que sor Juana hace referencia...” Más adelante, 258, Ortiz explica cómo esta característica da como resultado una armonía en espiral: “...el temperamento igual... permite producir un círculo perfecto de los intervalos de quinta, mientras que sor Juana se basa en el sistema pitagórico que por su pureza interválica produce una línea espiral”. Es decir, el temperamento igual, moderno, elimina la coma pitagórica y elude los tonos incantables del sistema pitagórico cerrándose en un círculo.

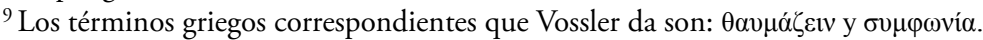


encuentra en la creación y la que nosotros vamos descubriendo en el orden y concierto de todos sus poéticos señalamientos.

FiciNo y JÁMBLICO: LOS SÍMBOLOS NEOPLATÓNICOS Y MUSICALES

Es curioso observar que en el terreno de la crítica musical, la tarea fundamental es evidentemente depurar la teoría de todo aquello que obstaculiza la formulación precisa de los elementos esenciales de la música. Sin embargo, cuando se trata de estudiar el tema de la música en la literatura, nada más lejos del interés crítico que desechar todas esas "antiguallas" sobre el arte musical con las que Pietro Cerone, por ejemplo, llenó la primera parte de su obra. Es precisamente ese cúmulo ideológico de fábulas y leyendas que tan estorbosas son a la nívea especulación de las proporciones y valores musicales donde encontramos el acervo imaginario que alimenta la simbólica poética y filosófica del Siglo de Oro. La lectura atenta de las páginas de Cerone es todavía una asignatura pendiente sobre el papel de la música en el universo simbólico de sor Juana. Un ejemplo de esto, para empezar, sería la versión musical del pliegue alma/cuerpo que nos ofrece Cerone, imbricada por virtud de las proporciones con el concepto de armonía:

estas dos cosas tan distintas no están ligadas con algún vínculo corporal, sino con una virtud causada de la proporción en que Dios compuso los humores en el hombre... Diremos pues que de dos cosas distinctas como son el ánima y el cuerpo, en el hombre nace la música humana... Adonde siendo necesario confessar que entre el cuerpo y el alma aya proporción, también es menester dezir que entre ellos ay una encubierta harmonía y Música: la qual tanto quanto dura, tanto nuestra alma está a su cuerpo unida. Mas como se rompe la dicha harmonía, es gasta esta Música y luego viene la muerte; es a saver la división del ánima y del cuerpo (206)..$^{10}$

Detrás de esta convicción, por atávica que pudiera parecer, podemos rastrear toda una historia pneumática y daimónica que la Antigua Grecia cultivaría para una posteridad de milenios. En el Renacimiento,

${ }^{10}$ En lo sucesivo modernizaré las grafías de las citas de Cerone. 
Marsilio Ficino se abocó a la recuperación de las versiones tardoantiguas de estas nociones, sobre todo a partir de las obras de Jámblico, la Vida de Pitágoras y Sobre los misterios egipcios. La llenadura del receptáculo humano por la inspiración o enthousiasmos, esto es, una fuerza sobrenatural, divina, así como su vaciamiento (Tomlinson: 204), ${ }^{11}$ Ficino los explicaba esforzándose por traducir a términos cristianos la posesión por un dios o daimon: el endiosamiento místico, tal como lo describía Jámblico:

decimos lo siguiente, que sonidos y melodías están apropiadamente consagrados a cada uno de los dioses, que les ha sido asignada una connaturalidad de una forma apropiada al rango y poder propio de cada uno, a los movimientos del universo mismo, a los sonidos armónicos que como silbidos emiten los movimientos. Según tales parentescos de las melodías con los dioses tiene lugar su venida (pues no hay nada que les suponga obstáculos), de suerte que lo que posee una semejanza fortuita con ellos participa de ellos inmediatamente, e inmediatamente se da una posesión perfecta y plenitud de esencia y poder superiores (115).

Para Jámblico existen muchas formas de teoforías o posesiones divinas y son multiformes los signos de los inspirados (110-111). Y aunque negó que la música pudiese suscitar el enthousiasmos o furor, afirma que la música puede atraer a los dioses (cfr. Gil: 310). Según cada furor, puede tratarse de voces armónicas o lo contrario, inarmónicas. Puede tratarse de la voz y del tono o de los intervalos intermedios de silencio. Otras veces es por la desigualdad o disonancia de los sonidos musicales. Por su parte, en su De vita coelitus comparandum, o Cómo entonar la vida con el universo, Ficino propone tres reglas para la composición de los cantos rituales con los cuales es posible sintonizar con las fuerzas del mundo creado por la divinidad. Para empezar, conocer las constelaciones y los astros, luego saber qué astro gobierna a la persona o al lugar y observar cuáles son los tonos y cantos que les son afines y, finalmente, observar cotidianamente las estrellas y sus posiciones para saber qué discursos, danzas, cantos y comportamientos pueden ser incitados por

${ }^{11}$ El autor observa que Pomponazzi no admitió el vaciamiento del alma, aunque sí su posesión divina. Quizá en este aspecto sor Juana se encuentre entre Ficino y Pomponazzi. 
ellas (2006: 150-151). Así vemos cómo el giro característico del pensamiento de Jámblico, situando la voluntad divina como la única clave de la inspiración y el papel de la música no como incitadora del furor en el hombre, sino como invocación e invitación a la voluntad divina, será vertebral en la postura filosófica de Ficino, quien adaptó las ideas paganas de Jámblico a la religión cristiana, que descansa sobre el principio de la Providencia.

Más aún, estas fuerzas espirituales que Ficino, por influjo de sus lecturas de los neoplatónicos paganos de la Antigüedad tardía llamaba también dáimones, inducidas o expulsadas del cuerpo mediante la música, hacen a la música misma corpórea, poseedora de una forma particular de índole sutil o fantasmal, sólo perceptible por el oído y la imaginación pero capaz de despertar el movimiento del cuerpo humano. Influido también por los pensadores y científicos árabes, como Al-Kindi, Ficino consideraba que las palabras y los cantos emiten rayos (Tomlinson: 118). En su comentario a El sofista (129), Ficino también deja ver la huella en su pensamiento del neoplatónico de los siglos IV y v Sinesio de Cirene, quien afirmaba que la fantasía o spiritus phantasticus está ligada a Dios y a los dáimones. ${ }^{12}$ Ficino demonizó, a la manera de los filósofos alejandrinos, su teoría de la armonía como percepción fantasmática. Y aunque esto le crease algunos problemas con las autoridades eclesiásticas — siendo él mismo sacerdote y oficiante- su obra tuvo una proyección decisiva en la cultura de los siglos siguientes, el XVI y el XVII, trascendiendo sus conceptos a muchos de los símbolos de los artistas barrocos. El favor de los Médici creó una barrera protectora para Ficino, a quien de todos modos se le suprimieron capítulos y modificaron sus obras donde parecían más atrevidas, ${ }^{13}$ pero aun así podemos aseverar que la difusión de sus escritos nunca fue prohibida por la Iglesia y que éstos podían ser leídos libremente en España, como lo atestigua el gran conocedor de los índices inquisitoriales Marcelino Menéndez Pelayo (309-310). Es decir, que prevaleció la definición de

${ }^{12}$ Ficino 1576, Comentario a "El sofista", cap. XLVI, "De operibus artis divinae atque humanae, et demonibus, et imaginibus atque umbris": 1292. Ver también su traducción del De insomniis, de Sinesio, 1576: 1971.

${ }^{13}$ Por ejemplo, el capítulo 27 dedicado a los dáimones en su Comentario al Timeo, presente en la edición de Basilea 1576 y suprimido en la edición de París, 1612, de sus Opera. 
Ficino de los dáimones según la teoría radial de Al-Kindi, como fuerzas de tipo neumático que forman parte del alma del mundo:

la materia misma del canto es más pura y mucho más parecida al cielo que la materia de una medicina. Es, en efecto, aérea, cálida o tibia, espira y en cierto modo vive, está compuesta en sus partes y miembros como un animal y no sólo tiene en sí el movimiento y manifiesta el afecto sino que trae además consigo un significado, poco menos que como el de una mente, hasta tal punto que podría en cierto modo ser definida como animal aéreo. ${ }^{14}$

Estas ideas permanecieron vigentes durante mucho tiempo antes de la revolución científica desatada por el racionalismo. Un ejemplo es cómo las nociones neumáticas — derivadas de la idea de que el mundo fue creado por un soplo divino- todavía son palpables en el Primero sueño de sor Juana cuando inicia con la mención de la sombra nocturna. El elemento gaseoso es lo primero que aparece en el poema, pues la descripción de la sombra nocturna la equipara a los vapores exhalados por la tierra, una convención de origen aristotélico, retomada por los escolásticos y que fue compartida por Carlos de Sigüenza y Góngora en su descripción de la formación de los cometas (256). ${ }^{15}$ El ceño de la sombra no puede alcanzar las estrellas:

la tenebrosa guerra

que con negros vapores le intimaba

la pavorosa sombra fugitiva...

(Cruz: vol. I, 335, vv. 7-9)

La sombra, por tanto, sólo se llena de su propia densidad:

14 "Cómo acrecer la vida en virtud de los astros" (De vita coelitus comparanda), en Ficino 2006: 151.

15 “...porque, así como fue conveniente que en el globo terráqueo hubiese no sólo plantas y árboles venenosos, sino víboras, sierpes, alacranes, escuerzos, dragones, basiliscos para que según la combinación de sus cualidades atrajesen a sí con violencia simpatética los hálitos, expiraciones y efluvios venenosos y mortíferos de la tierra y cuerpos metálicos... de la misma manera era necesario que hubiese alguna cosa donde se juntasen y consumiesen los hálitos, vapores, expiraciones, y los efluvios venenosos que pasaron a la región del aire...”. Ver también Soriano Vallés: 20. 
quedando sólo o dueño

del aire que empañaba

con el aliento denso que exhalaba...

(vv. 16-18)

Pero la presencia del pneumatismo va más allá de esta comparación. La música concebida como un efluvio que se expande también es muy antigua y está relacionada con una operación terapéutica y mágica que los griegos llamaban epodé y los latinos incantum (Gil: 217). Distinta y a la vez afín al arte musical, la epodé es fundamentalmente verbal, algunas veces recitada y otras cantada. Y si la inspiración o la posesión - Ficino las llamará furores - y el exorcismo y la catarsis están ligados desde la Antigüedad hasta el Renacimiento con determinados procedimientos terapéuticos, será Marsilio Ficino el que dará a estas ideas un ropaje cristiano en el que la Gracia divina y las fuerzas universales son las que realizan lo que para Jámblico y los autores antiguos eran las operaciones de los dioses y los dáimones. Las virtudes de la oración, los ensalmos y la locura divina o éxtasis tenían para pitagóricos, platónicos, estoicos y neoplatónicos (257) esta virtud fluida que se deja ver hasta hoy en las imágenes poéticas, pues para ellos la música es divina. Galeno mismo reconoció esta dynamis y su relación con la medicina es precisamente la que Ficino desplegará en todos los libros de su De vita, sobre todo el dedicado a la armonía del hombre con las fuerzas celestes.

\section{Los efluvios daimónicos del PRIMERO SUEÑO}

Según Luis Gil, Heródoto describió la epodé de los persas, sus ritos y ensalmos, como una logoterapia sicosomática frecuentemente acompañada de instrumentos musicales (229). En la Odisea la epodé aparece asociada a una praxis o ritual. Está relacionada también con el silentium mysticum del terapeuta al tratar al enfermo (241). Desde Tales de Mileto, se consideraba el aire la sede de los dáimones y es así como éstos pueden causar enfermedades o curarlas; la música tiene la virtud de expulsarlos, para lo que solían utilizar las disonancias, o de inducir determinadas conductas, como el apaciguamiento, llamado por Horacio dulce lenimen o dulce solaz (293; Oda I, 32, 15, de Horacio). El concepto materialista del espíritu como un fluido ventoso es claramente 
perceptible en el coro disonante de las aves nocturnas en estos versos del Primero sueño:

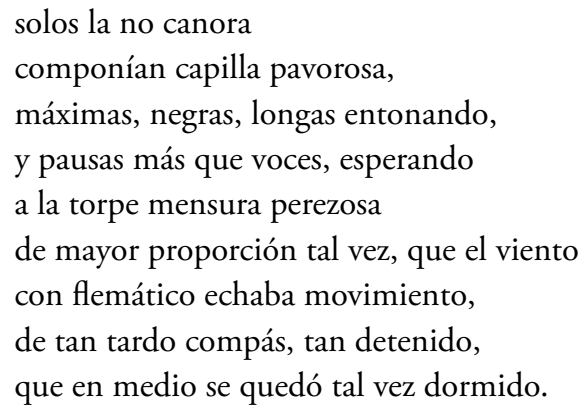

La "torpe mensura" del viento aparece así asociada al temperamento flemático, cuya conducta se vincula psicosomáticamente al humor segregado por la glándula pituitaria. Esta música, por tanto, invita a la introversión, a la tranquilidad y al sueño. Si volvemos a Jámblico, este "triste són intercadente" (v. 65) del poema de sor Juana está muy lejos de simbolizar el pecado o la torpeza del mundo material, como algunos han creído omitiendo que son las aves consagradas a Minerva y emblema de la sabiduría y la prudencia (Pascual Buxó: 113-116), ${ }^{16}$ sino que además el sentido de su aparición en el poema es de carácter musical; "la altura del tono o los intervalos intermedios de silencio", el aumento o disminución de su intensidad musical, predisponen al oficiante a la posesión divina (Jámblico: 111). El "triste són" propicia convenientemente, en fin, la descripción poética del fenómeno del sueño a partir del funcionamiento vegetativo del organismo humano, elevándose al cerebro con los espíritus cristalinos y proyectándose a la contemplación del mundo desde la enorme altura del orbe donde se encuentran los conceptos universales o las "intelectuales claras" estrellas (v. 287), casi en el pináculo del intelecto agente. Pero no se trata tampoco de una canción de cuna, pues la disonancia de las aves consagradas a Minerva,

${ }^{16}$ La lectura freudiana de los epónimos Nictimene, Ascálafo o el epónimo virtual de Mineidas ("aquellas... a la deidad de Baco inobedientes") oblitera completamente el sentido conceptual, agudo, anagógico, de la presencia de estas aves en el Primero sueño. Ver también Olivares Zorrilla 2008: 254-255; 268. 
cuyas voces finalmente acaban por apagarse en los silencios, a la vez que sosiegan el ánimo, motivan y aconsejan mantener la guardia. Ficino, por su parte, en una de sus cartas (cfr. Voss: 32) describe la escala musical como una secuencia de consonancias y disonancias, siendo las consonantes do, mi y sol, y las disonantes, sobre todo re, en menor grado fa y finalmente si. Pero todas ellas conducen a la perfección divina y son comparadas por él con el orden de las nueve Musas. La pausada disonancia de las aves nocturnas tiene, pues, un sentido teleológico. Es un verdadero pharmakon (Gil: 293) que propicia el ascenso espiritual, pathos y ethos del alma, induciendo a un sueño vigilante. Este trance anímico es el que convendrá con el resto del poema, cuya finalidad es precisamente entonar el alma con el cosmos en un sueño consciente, alerta. Para ello es capital el valor del silencio, pues no se trata sólo del silencio de los seres vivos durante la noche y el sueño, sino también del silencio teologal que, de acuerdo con san Agustín, abre la atención a los sonidos interiores, que así pueden aproximarse intelectualmente a la música mundana o celeste. Para el filósofo cristiano, la música es intemporal y — sólo como manifestación fenoménica- temporal, pero siempre debe tender al silencio, de lo sensible a lo inteligible. ${ }^{17}$ La mística hispánica ha expresado poéticamente este particular silencio, como san Juan de la Cruz:

¡Mi amado, las montańas,

los valles solitarios nemorosos,

las ínsulas extrañas,

los ríos sonorosos,

el silbo de los aires amorosos;

la noche sosegada,

en par de los levantes de la aurora,

la música callada,

la soledad sonora,

la cena que recrea y enamora...

(“Cántico espiritual”: 233)

\footnotetext{
${ }^{17}$ Agustín de Hipona: XVII, 14, 492: "Fue David varón muy diestro y aficionado a componer canciones, y dado al eco y armonía de la música, no llevado del gusto común y vulgar, sino penetrado de una intención y ánimo devoto y fiel, pues con ella sirvió a su Dios, que es el verdadero Dios, figurando místicamente con la música un arcano grande y excelente". Ver Mazzeo: 195.
} 
El silencio de la voz se convierte de este modo en canto interior y espiritual en comunión con la armonía universal.

\section{El SILENCIO ELOCUENTE ES PNEUMÁTICO}

Por su parte, Pietro Cerone tiene algunos pasajes, como el titulado "Del neuma usado en cantollano", donde considera el carácter espiritual de la música. Tomando el concepto de Gaffurio sobre el neuma como voz de una sola respiración, asevera:

El Neuma es un excessivo gozo y alegría del alma causada por el desseo de las cosas eternas [...] declara el gozo y el amor de los creyentes y quanta alegría y alabança se ha seguido por la fe, oída la predicación. Se haze el Neuma en una sola y confinal sylaba de la palabra, para mostrar que las alabanças de Dios no se pueden dezir, ni comprehender, ni alcançar... (265-266).

Añade un comentario sobre el mismo tema en el que encontramos un paralelo de otro de sor Juana en su Respuesta:

Alleluia es poca cosa en la palabra y mucha en Neuma, porque aquel gozo es mayor de lo que se puede explicar con palabras; y entonces hablamos con mayor eloquencia las obras de la Omnipotencia divina, cuando quedando maravillados y atónitos, las callamos: y entonces el hombre alaba convenientemente callando lo que no puede convenientemente significar hablando (267).

El siguiente fragmento de sor Juana parece un eco de estas palabras de Cerone:

aquellas cosas que no se pueden decir, es menester decir siquiera que no se pueden decir, para que se entienda que el callar no es no haber qué decir, sino no caber en las voces lo mucho que hay que decir (vol. IV: 442, líneas 79-83).

Ese "decir" lo que no se puede decir es, evidentemente, una expresión no lingüística, como lo es con exactitud el neuma en cantollano. Y todo esto se vincula finalmente con una perspectiva afectiva de la mú- 
sica, algo que Francisco Salinas comenta hacia el final de su obra. Citando a Teofrasto, Salinas sostiene que los afectos estimulan con fuerza el ingenio de poetas y músicos creando poemas y cantos sublimes:

ellos mismos forman, ayudan a la música, innata y congénita en nuestros sentidos, y la llevan más allá de lo que es propiamente el ingenio. Así lo enseña el ejemplo de aquellos que, inspirados por el sagrado furor, prorrumpen en enthusiasmo con mayor sublimidad y no parece que suena a algo mortal lo que cantan (766).

Esto nos lleva de nuevo a los postulados de Marsilio Ficino en sus Divinos furores y en su De vita: la armonización de lo humano con lo celestial. El regreso constante de sus ideas al observar las obras de sor Juana bien puede fundar aquí el principio de que la idea de la armonía, la concepción de la música de sor Juana, es imposible de entender fuera del alcance de las múltiples órbitas del influjo ficiniano. A la vez, el impulso de llevar a las últimas consecuencias las teorías del neoplatónico florentino evidencia la esfera barroca donde sor Juana las explora, las pone a prueba y propone un corolario. Podemos también decir con Gilles Deleuze (capítulo 9, "La nueva armonía": 164) que si lo que distingue a la música barroca es "extraer la armonía de la melodía", siendo relacionadas entre sí las distintas artes como líneas melódicas sobre las cuales se eleva la armonía universal, sor Juana cumple con esta condición que supera la relación con un centro (161) optando por el vértice instaurador del universo infinito. Opción ciertamente barroca, cuya excentricidad no equivale ni al caos ni a la anarquía, sino al apercibimiento de la condición abierta e inacabada de la realidad, cuyos tientos o "ambages" (v. 715) van signados, al fin, por el concierto de lo trascendente.

\section{LA ARMONÍA DEL MUNDO}

Las ideas musicales de sor Juana en distintas partes de su obra parecen apegarse a una idea de la armonía en la cual consonancias y disonancias se unen en el plan universal (siendo la trascendencia del mundo material el fin de las disonancias), más que a un moderno temperamento igual que se abría ya paso desde fines del siglo xv, como 
podemos ver en el tratado de Bartolomé Ramos Pareja (parte I, tratado 2, cap. 5: 50-57), y se practicó de manera creciente en los siguientes siglos. A pesar de ello, la verdadera postura transmusical, por así decirlo, de sor Juana es la de un temperamento sinérgico entre la dimensión humana y la celestial. A fines del siglo xv, Ficino ya había propugnado por él a través de una terapéutica que revitalizaba la concepción fluida y armónica del universo del pensamiento neoplatónico alejandrino. $\mathrm{Y}$ en esto consiste también la verdadera templanza de sor Juana: su preocupación por la comprehensión humana, según sus propias limitaciones y capacidades, de la numinosidad y trascendencia espiritual de la armonía.

Su concepto de la armonía como una espiral, como veremos más adelante, es retomado por ella precisamente de la obra de Ramos Pareja. Lo encontramos en su romance 21 (vol. I: 64, vv. 53-60), donde explica por qué tituló El caracol al tratado de música que ella había reformulado a partir de El melopeo y maestro, de Cerone, y que tanto ha intrigado a los lectores modernos:

En él, si mal no me acuerdo,

me parece que decía

que es una línea espiral, no un círculo, la Armonía;

y por razón de su forma

revuelta sobre sí misma,

lo intitulé Caracol,

porque esta revuelta hacía.

El intento por resolver este enigma ha producido un sinnúmero de propuestas que quizá podríamos dividir en dos vertientes. La primera sería la estrictamente musical —ya mencioné a Méndez Plancarte, a Pamela Long y a Mario Ortiz, quienes encuentran la respuesta en la misma armonía pitagórica. La segunda vertiente es más bien extramusical, es decir que se trata de aquellos que explican la idea de sor Juana mediante elementos no pertenecientes a la música. Ortiz menciona en una nota (258) a Octavio Paz, quien recurre a los aparatos acústicos que Atanasio Kircher ilustra en su Musurgia universalis (Paz: 316-317), muchos de los cuales forman la figura del caracol. Otra coincidencia es la concepción en espiral o ricorso del fluir de los acontecimientos his- 
tóricos de la que habla Giambattista Vico ${ }^{18}$ tres décadas después de la muerte de sor Juana, lo que constituiría una "armonización" más de la poeta novohispana con la ciencia de su época. Yo misma he sugerido en otro lado (Olivares Zorrilla 2012: 349) la estética de la arquitectura barroca, que había introducido precisamente en el siglo Xviı la columna salomónica; también recuerdo haber mencionado el tratado De arquitectura recta y oblicua, de Juan Caramuel, ${ }^{19}$ donde este influyente autor barroco encuentra las connotaciones espirituales de las escalas en forma de caracol que adornan los coros de las iglesias. Además tendríamos

18 "Ora con tal Ricorso di cose Umane Civili, che particularmente in questo Libro si è raginato, si rifletta su i confronti, che per tuta quest' Opera in un gran numero di materie si sono fatti circa i tempi primi, e gli ultimi delle Nazioni Antiche, e Moderne: e si avrà tutta spiegata la Storia, non già particolare, ed in tempo delle Leggi, e de' fatti de' Romani, o de' Greci, ma sull'identità in sostanza d'intendere, e diversità de modi lor di spiegarse; si avrà la Storia Ideale delle Leggi eterne, sopra le quali corron'i Fatti de tutte le Nazioni, ne' loro sorgimienti, progressi, stati, decadenze, e fini, se ben fusse, lo que è certamente falso, che dall'Eternità di tempo in tempo nacessero Mondi Infiniti" (524) ["Ahora bien, con tal recurso de las instituciones humanas civiles a que hemos dado particular atención en este libro, reflexionemos sobre la confrontación que por toda esta obra se ha hecho de un gran número de materias así como hechos sobre los tiempos primeros y los últimos de las naciones antiguas y modernas: y se desplegará toda la historia, no ya la particular de tiempos de la Ley y de los hechos de los romanos o de los griegos, sino sobre la identidad sustancial en la forma de entenderla y la diversidad de modos de despliegue que tienen; se tendrá la historia ideal de las leyes eternas, sobre la cual concurren los hechos de todas las naciones, el momento de su surgimiento, de su progreso, su consolidación, su decadencia y su fin, como si fuese, lo que es ciertamente falso, que nacieran de tiempo en tiempo en la eternidad mundos infinitos"].

19 "Juan Caramuel, por su parte, en su Architectura civil recta y obliqua, se adhiere a la teoría de Vitruvio sobre la euritmia arquitectónica... La conmodulatio que resulta equipara los acordes de los intervalos musicales con las proporciones del edificio. Caramuel nos habla 'De algunas ciencias que adornan la architectura', entre ellas la música y la astronomía. Asimismo trata sobre las escaleras de caracol, favorecidas por el Palatinado y por los húngaros, mas no tanto por los españoles. No obstante, dice, son de caracol las escaleras de las torres, así como aquéllas que sirven para subir al órgano y a las tribunas en las iglesias. Llama Cruz de los Arquitectos la escalera de caracol del teólogo Fray Ángel, quien sin ser arquitecto ha admirado al mundo con esa fábrica, que 'examinan todos y entienden muy pocos', y que le merecía a su artífice el ser catedrático de prima en Teología. A continuación describe el arte de esta 'marabillosa escalera', consistente en aumentar el ancho de las piedras en la parte superior [Juan Caramuel, Arquitectura civil, recta y oblicua, 1678: 18]" (356-357). 
que considerar que $\operatorname{Kepler}^{20}$ mismo había observado la trayectoria en espiral de los astros al nunca cerrar su órbita en el mismo punto de partida. Coincido con Ortiz en que la verdadera solución la tenemos que encontrar en el terreno mismo de la música, puesto que se trata precisamente de un tratado de esta índole. Para mí es evidente, no obstante, que no podemos obviar el sentido teológico que toda esta concepción encierra. Las demás concurrencias simplemente coadyuvarían a esta propuesta que, como digo, sor Juana encuentra en Bartolomé Ramos Pareja.

\section{La espiral armónica de Ramos Pareja y Gaffurio}

La difusión en España de la Música práctica, impresa en Boloña en 1482 y escrita originalmente en latín, no sólo es innegable, sino decisiva a lo largo del siglo Xvi. Francisco Salinas es un firme defensor de las teorías de Ramos Pareja y, sobre todo, toma su partido en relación con las diferencias que tuvo el tratadista del siglo XV con su contemporáneo Franchino Gaffurio. Veamos lo que Ramos dice a la letra:

Con base en aquello de lo que la música tomó origen, según opinión de Hesíodo, dispondremos de tal manera a las nueve Musas... en su lugar debido, siguiendo la autoridad de Marciano y de Boecio. Así también atribuiremos a cada una un verso por el que se indique su conveniencia con la música. Las dispondremos, pues, de modo que Talía tenga el silencio, como la Tierra. Luego atribuiremos a Clío a la Luna; a Calíope se la dedicaremos a Mercurio y a Terpsícore se la asignaremos a Venus. A Melpómene la adornará el Sol. Erato incitará a Marte, a Euterpe la hace benévola y placentera Júpiter: en cambio, a Polhiminia (sic) la contrista Saturno. A la última, Urania, el cielo estrellado le dará hermosura y descanso. Pues bien, si trazamos un círculo desde la primera, es decir, el silencio, hasta la última, y volvemos a la segunda repitiendo hacia abajo todo el canto, creamos el hipodorio. Y estimamos que se debe de hacer con todas como con esas, de manera que no dejemos de trazar espirales hasta que lleguemos a la última musa... (76-77).

${ }^{20}$ Johannes Kepler, Astronomia nova, seu physica coelestis tradita commentariis de motibus stellae Martis ex observationibus G. V. Tychonis Brahe, Jussu \& sumptibus Rudolphi II. Romanorum Imperatoris \&c., 1609, Pars Tertia, cap. 32: 125-126 (Olivares Zorrilla 2009: 61). 
Ramos Pareja ilustra con el siguiente grabado su descripción:

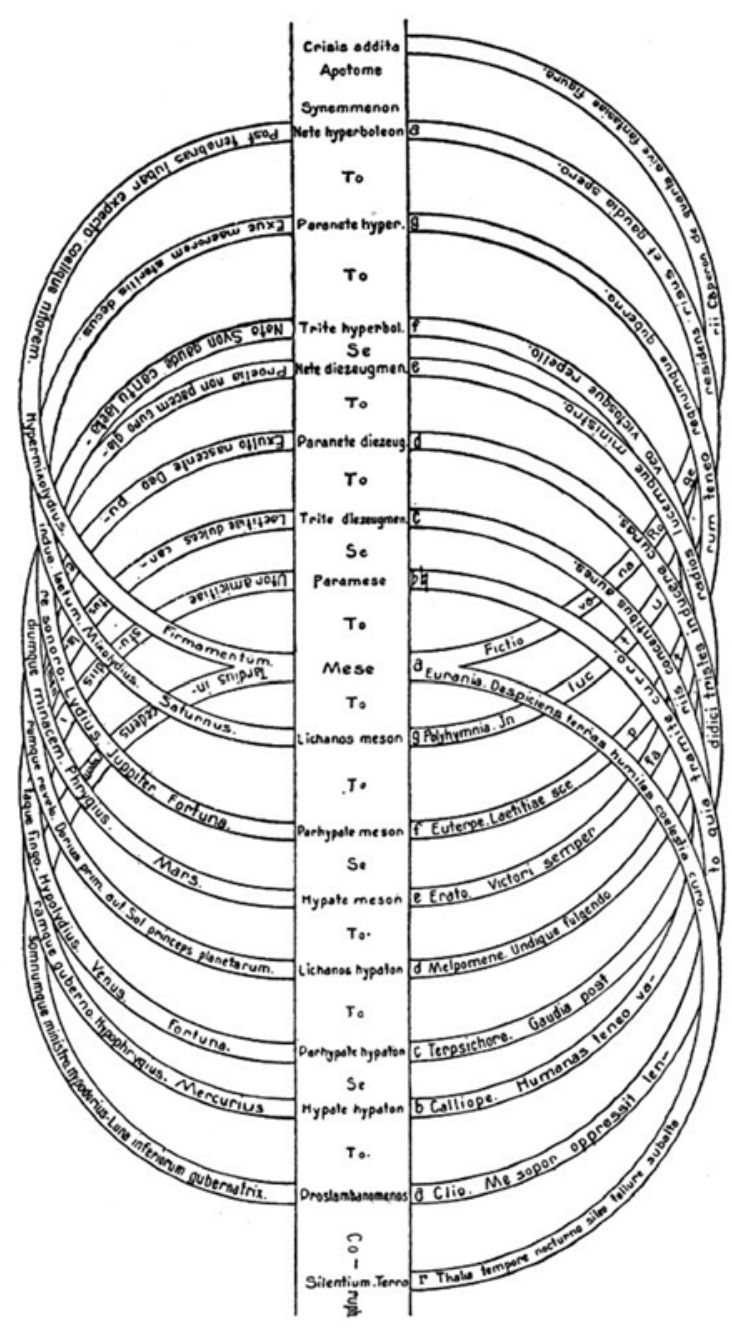

Bartolomé Ramos Pareja, Musica practica, 1482.

Esta múltiple relación entre las Musas, los planetas y los modos musicales en asociación armónica la toma Gaffurio casi textualmente de 
Ramos Pareja, ilustrándola a su vez, en su Practica Musicae de 1496, con las figuras de Apolo, las Gracias y las Musas sobre un híbrido entre el Cancerbero y la serpiente Pitón.

PRACTICA MVSICE FRANCHINI GAFORI LAVDENSIS.

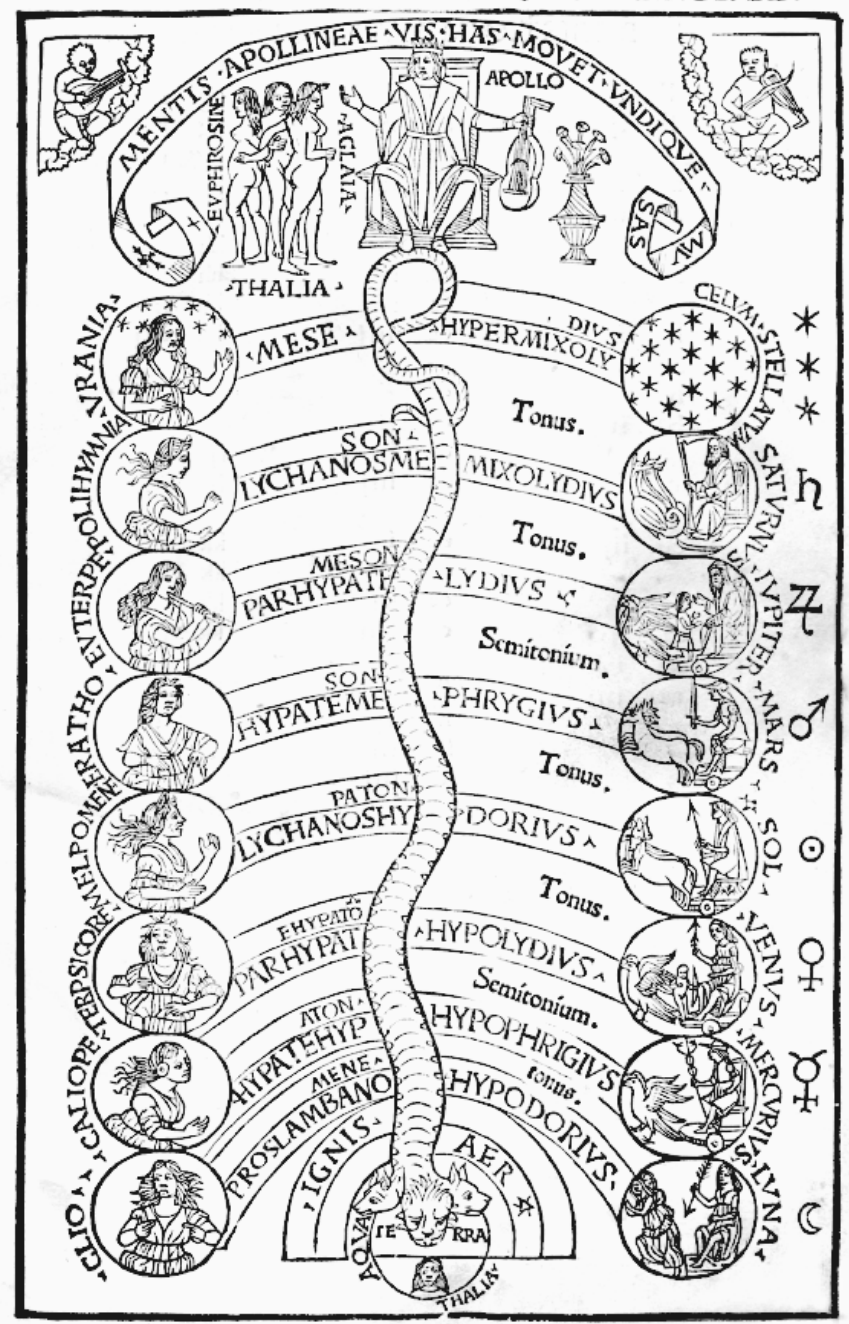

Franchino Gaffurio, Practica musicae, 1496. 
James Haar $(20)^{21}$ fue quien en el siglo xx puso en claro que el famoso frontispicio de la Practica musicae de Gaffurio está en absoluta deuda con Ramos, a quien el italiano no dio crédito alguno. He aquí, pues, el verdadero contexto del título de El caracol, de sor Juana. Como podemos ver, la armonía de la Musa inferior con la superior regresa a la segunda de la secuencia, la cual establece relación con el correspondiente tono opuesto de la octava contigua y así, sucesivamente. Como esta es una ilustración de la armonía y no melódica, según la oportuna distinción Mario Ortiz (258; n. 17), se trata, por tanto, de una concepción íntegra y abarcadora del fenómeno musical. Con esto queda claro que el tratado de Cerone no fue la única fuente consultada por sor Juana y que ella indagó más allá en otros tratados que circulaban en su tiempo. Vista con mayor contexto, la relación entre los intervalos y los planetas que encontramos en Cerone, ${ }^{22}$ es una expresión muy difun-

${ }^{21}$ Señalé la relación con la idea de la armonía de sor Juana en mi tesis defendida en 1999, hoy publicada con el mismo título y con las ilustraciones de ambos tratados musicales. Ver Olivares Zorrilla 2012: 354-356.

22 "Mas puesto caso que entre aquellas espheras y cielos no aya sonido sensible, como quieren Platón, Aristóteles y otros, ¿quién quiere denegar que a lo menos no se halle entre ellas una consonancia muda que procede de las proporcionadas distancias? Cierto, si queremos creer a los que con verdadera sciencia miden los intervalos que hay entre los cielos; sin duda confesaremos ser (sic) ahí una espiritual harmonía por ser distantes en harmónica proporción. Ellos no sin doctrina affirman que desde la Tierra a la Luna hay el espacio de 126 mil estadios (siendo un estadio de 125 pasos, que es la vigesimocuarta parte de una legua) y este dizen ser el espacio del Tono; que apunto es aquel intervalo (respeto a los otros) que los músicos prácticos consideran entre re y mi. Después van poniendo desde la esphera de la Luna a la de Mercurio un poco más de la mitad del dicho espacio: el qual según las proporciones de la música es el intervalo del semitono cantable. De la esphera de Mercurio a la de Venus dicen que hay casi otro tanto espacio, y es la distancia del Semitono incantable. Desde Venus al Sol hay casi otro tanto, como todo lo sobredicho hasta aquí; y es el intervalo de una Tercera menor, o de un Tono y un Semitono cantable, que es tanto como desde la Tierra a Mercurio. Dende el Sol a Marte dizen que otro tanto espacio hay, como desde la Tierra a la Luna, que es de un Tono. De Marte a Júpiter un poco mas de la mitad, que es el Semitono cantable. Desde Júpiter a Saturno, un poco menos del dicho espacio, que es la distancia del Semitono incantable. Finalmente desde Saturno hasta el zodiaco o postre cielo (que es el cielo estrellado) dezían que había el mesmo espacio que hay desde Marte a Júpiter, que es el Semitono cantable. De manera que desde al postrer cielo a la Esphera del Sol se comprehende el espacio de la Dyathessarón: y desde la esfera del Sol a la Tierra, el de la Diapente. Mas desde la Tierra al postrer cielo hay la Dyapasón, consonancia perfecta. Y adviertan que quanto más los círculos o planetas son más bajos y más cerca a la Luna, causan sonido más grave, y quanto son más altos y más se allegan al ciel más alto, 
dida en buena parte de los tratados musicales desde la Antigüedad y la toma él ya sea de Gaffurio (12a y 12b) o de Zarlino (I: 12-13); era una costumbre entre los tratadistas citar ese ejemplo ilustrativo del sistema pitagórico como lo era la mención de la música de David apaciguando a Saúl, algo que sor Juana menciona también en su Respuesta y que pudo llegar hasta ella desde múltiples fuentes. De hecho, el ejemplo anterior es lo que fundamenta esquemáticamente el famoso regateo de Abraham en la Respuesta de sor Juana, pero sobre todo es una expresión más de la idea de armonía que sor Juana invoca en el Romance 21 y que ella probablemente lee y ve ilustrada con estas espirales ya sea en Ramos Pareja o en Gaffurio. El regateo por los justos de Abraham en la Respuesta, claramente inscrito en la teoría pitagórica precisamente por tratarse de un asunto divino, hace eco, además, de la escuela alegorista de interpretación bíblica, representada por Filón de Alejandría y algunos Padres de la Iglesia, como Clemente y Orígenes, en la que prevalece la idea de que todos los asuntos humanos, incluidas las ciencias, tienen su paradigma en las Escrituras, siendo posible rastrear dicha tendencia en los libros escritos por las órdenes religiosas, tarea a la que se abocó, como apunté antes, Raymundo Lida.

$\mathrm{Si}$ tenemos en cuenta la filosofía del Renacimiento, nos percataremos también de que la espiral armónica de Ramos Pareja está relacionada con el Comentario al "Timeo" de Ficino, quien observaba la trayectoria de ida y vuelta de las ondas del sonido formando círculos y, en el caso de la armonía musical, formas ovoides, puesto que la música está compuesta por notas bajas y notas altas:

la octava nota, como si continuara por sí misma la anchura de la primera nota a través de su vértice más agudo, ahora hace una sola nota de sí misma y de la primera; y así como el ojo ve una curva ovalada como figura única, aunque sea mayor en una dimensión y menor en la otra, así el oído parece sacar una sola nota que resulta de la nota profunda y la octava y se eleva gradualmente y con dulzura desde el sonido profundo y pleno en un ascenso contenido, como la forma de un huevo (1641, cap. 30: 412; trad. mía).

resonan más agudamente" (223-224). Algunas incongruencias lingüísticas se explican por el origen italiano de Cerone. 
Los vaivenes armónicos de los que habla Ramos Pareja responden a esta explicación del Timeo, pero, como sucede con las órbitas de Kepler, nunca se cierran los óvalos sobre sí mismos, formando epiciclos o trayectorias en espiral. Observación que, por cierto, ya había hecho antiguamente Apolonio. Cuando Ramos Pareja estuvo en Italia, las obras de Ficino eran ampliamente leídas y se buscaba, bajo su influjo, la correspondencia de las ideas neoplatónicas y pitagóricas en todos los órdenes del conocimiento. Es muy posible que la lectura de sor Juana del tratado de Ramos - o por lo menos su aproximación "noticiosa"se debiera al influjo de otro tratado, el de Francisco Salinas, también muy difundido en los siglos xvI y xVII.

\section{SALINAS Y EL TEMPERAMENTO IGUAL}

Ya desde el siglo XVI, Salinas parece aceptar las innovaciones de Ramos Pareja que avanzaban en el siglo xv sobre lo que sería el temperamento igual. La obra de Salinas, Siete libros sobre la música, de 1577, entabla una explícita afinidad con las teorías de su contemporáneo Zarlino, como éste a su vez con las de Salinas (Hernando González: 971), sobre todo en lo referente a su "sistema perfecto" para órgano, otro avance sobre el temperamento igual. Es notable cómo a diferencia de Gaffurio y muchos de sus seguidores, Salinas opta por criticar ampliamente el sistema pitagórico y los absurdos que de él se derivan, entre ellos la consideración de los pitagóricos sobre el intervalo comma, que tantos quebraderos de cabeza le ocasionaban a sor Juana en su romance 21 y ha explicado hoy ampliamente Ortiz. Es decir que en este tratado musical del siglo XvI hispano se marca una distancia con el esquema pitagórico, optando por un temperamento capaz de abrazar, sin el estorbo de las "voces incantables", la ejecución de los variados instrumentos en una práctica musical ya plenamente polifónica. Hacia el final de su obra, Salinas apunta ciertas consideraciones sobre la relación entre los intervalos y el alma:

De todas maneras, a estos movimientos celestes nunca los llamamos sonidos, ni en su sujeto, ni en su causa eficiente, según dicen los físicos... Eso hubiera sido la música sideral que no había de ser escuchada por nadie... Tampoco creo, pues, que sea necesaria esta música de los 
astros y de los elementos. Por tanto, todo aquello que se capta en la conjunción de los elementos naturales y en la diversidad de los tiempos, no lo aprende el oído, sino la razón, que constituye una de las partes del alma. En éstas se encuentran, al parecer, todas las proporciones de las consonancias. Así, la facultad racional dista del apetito irascible uno y medio, he aquí, pues, la consonancia del diapente; el irascible dista del concupiscible tres y medio, es decir, un diatessarón; por tanto, tenemos en el alma el diapasón perfecto. Más aún, en la música vocal, como en la instrumental, el diapente encierra dentro de sí al diatesarón, pero no al revés, y el diapasón contiene a los dos, pero no al revés. Pues bien, de la misma manera el alma sensitiva contiene dentro de sí al alma vegetativa, pero no al revés y el alma racional contiene dentro de sí a las otras dos, pero no al revés (34-35).

Estas reflexiones de Salinas pudieron ofrecerle la certeza a sor Juana de que sus dificultades con la coma pitagórica no eran exclusivamente suyas, y posiblemente que la armonía pitagórica era más una cuestión del alma humana que de la ejecución musical de su tiempo. Pamela Long considera que pese al predominio filosófico del modelo pitagórico en las consideraciones musicales de sor Juana, como compositora (y, ańadiría yo, como instructora de música de las pupilas del convento de San Jerónimo), ${ }^{23}$ se enfrentó a lo mismo por lo que atravesaban todos los músicos de su tiempo: la entonación de los diversos instrumentos según los distintos temples ya en uso: el temperamento justo o pitagórico (para las arpas), el temperamento medio (para los teclados) y el temperamento igual (para las cuerdas). Un conjunto instrumental tenía por fuerza que lidiar con esta cuestión (54-55 [tesis]; 36 [libro]). Long no se equivoca cuando considera que sor Juana simplemente no pudo ser una pitagórica al cien por cien y tratar de explicar con ello toda la realidad (ni toda la música). Se trata de un trance característico de los barrocos, quienes sintetizaron todas las propuestas en obras que solían tener propiedades multívocas. Soy de la idea de que tampoco podemos explicar por completo la obra de sor Juana (ni el fenómeno de sor Juana en sí) solamente a través del fascinante legado neoplatónico que parece ser la marca distintiva de su producción lírica. El asunto es mucho más complejo. Más complejo aún que sumar el legado aristotélico al plató-

${ }^{23}$ Es muy posible que su adaptación del tratado de Cerone a su Caracol se debiera precisamente a sus obligaciones académico-musicales. 
nico, como es propio del Renacimiento y el Barroco. No podríamos dilucidarlo si no es mediante una aproximación filológica que establezca la red sutil de relaciones que los contenidos de la obra sorjuaniana traban con lo que fue su biblioteca. Una biblioteca omnipresente pero escurridiza, confiscada, empeñada y perdida, convertida en pura virtualidad y cuya existencia solamente podemos fincar en la palabra escrita.

\section{LAS OPCIONES DE SOR JUANA}

Sor Juana fue seguramente una pensadora platónica y pitagórica por convicción filosófica y estética; pero también estuvo fuertemente inclinada a renovar sus conocimientos y ponerse al día en todos los órdenes. En realidad, pienso que no podemos acusarla de ser tradicionalista por el simple expediente de haber defendido la postura de fray Eusebio Kino en un soneto, ${ }^{24}$ ni que sor Juana creyese, cincuenta años después de que Nieremberg lo había negado categóricamente, que los cielos fuesen cristalinos (Nieremberg: libro VI, cap. VIII, 313-314). Al igual que el astrónomo jesuita y novohispano, fray Diego Rodríguez (Trabulse: 25-65; particularmente 60-65), así como con muchos científicos de la América colonial, prefirió adoptar una postura ecléctica tratando de conciliar lo antiguo y lo moderno, el dogma y el descubrimiento. Igualmente, en el terreno de la música, en su tiempo ya han pasado dos siglos de las innovaciones de Ramos Pareja, para quien las limitaciones de la escala pitagórica en la música práctica ya fueron evidentes y cuya solución por él propuesta repercutió enormemente en la música europea de los siglos siguientes. ¿Cómo podría afirmarse que sor Juana fue ajena a este vasto movimiento musical desplegado a lo largo de dos siglos a partir de Ramos Pareja? Pese a las resistencias de otros tratadistas, desde Gaffurio, la propuesta de Ramos Pareja terminó imponiéndose

\footnotetext{
${ }^{24}$ Kino debatía entonces con Sigüenza y Góngora sobre la naturaleza ominosa o no de los cometas y sobre su trayectoria infra o supralunar. La convicción antigua y medieval sobre la solidez de los cielos impediría aceptar que los cometas viajasen sobre la órbita de la luna. Sigüenza lo negaba categóricamente en 1680, como lo negó Juan Eusebio Nieremberg en 1630. Pero sor Juana acababa de conocer a la virreina, la condesa de Paredes, y debía congraciarse con ella para impulsar su propia carrera literaria; no podía antagonizar con el amigo de su mecenas. La decisión de defender a Kino, como vemos, no fue en vano.
} 
sobre todo en la afinación de las cuerdas. Doscientos ańos no son una bicoca y podemos afirmar con seguridad que para tiempos de sor Juana ya estaba firme la práctica de un temperamento no pitagórico. Los inventarios de libros que llegaban a la Nueva España en el siglo XvI demuestran cuán afectos eran los novohispanos a los manuales y tratados de música para vihuela. ${ }^{25}$ Pues bien, no existe música para vihuela en el siglo XVI y los siguientes afinada con el temperamento pitagórico, sino con el temperamento propuesto por Bartolomé Ramos Pareja. La denominación de esta revolucionaria propuesta va cambiando según el momento histórico, pero es indudable que al fin va a desembocar en el buen temperamento como lo desarrolla Juan Sebastián Bach. Sor Juana se encuentra a medio camino: como maestra de capilla del convento de San Jerónimo, ella tenía que aprender cómo templar diversos instrumentos. Jamás le hubiera bastado un solo temperamento, esa es la realidad. La espiral armónica de la que ella habla en su romance tiene todas las resonancias de la de Ramos Pareja y es el espacio idóneo de su búsqueda de respuestas y de alteridad.

Bien templada, en fin, entre sus numerosas fuentes de conocimiento, sor Juana es tan pitagórica como san Agustín, Boecio o Gaffurio; foguea su neoplatonismo en ideas de Sinesio, Jámblico o Ficino, y a la vez está en posibilidad de compulsar sus adquisiciones teóricas sobre música en Ramos Pareja, Salinas, Zarlino o Cerone desde una perspectiva típicamente barroca, de múltiples puntos de fuga, capaz de incluir en su espectro hasta las perspectivas ilusionistas. En su romance 21, la "coma que hay perdida", "el semitono incantable" y todo aquello que contraviene fácticamente la armonización instrumental es una fuente de perplejidades - perfectamente expresadas en su romance- que la llevan a invocar las cenizas de Pitágoras en busca de una solución que evidentemente él no le ofrece. No seríamos fieles a la verdad ni textual

${ }^{25}$ En Irving Leonard tenemos inventariados en el siglo xvi Vergel de música (272), de Martín de Tapia, y Libro de música en cifras para vihuela, Esteban Daza (327), además de Institutione e demostraçione armonice, de Josep Zarlino (329). En el siglo XviI, en la biblioteca de Melchor Pérez de Soto, tenemos nuevamente el Libro de música de Daza (53), además del Demostrationi armoniche, de Zarlino (65) y El Melopeo y Maestro, de Pedro Cerone (67). Los diversos libros sobre canto llano que se importaron a la Nueva España y la práctica eclesiástica de esta música de corte medieval fueron quizá el punto de quiebre que puso a sor Juana en disquisiciones entre una forma y otra de temperamento. 
ni contextual si la encerramos exclusivamente en el estuche pitagórico, por mucho que esta sea una tentación de quienes descubren algunos de sus rasgos en la obra de sor Juana. Esos rasgos no son los únicos, pues estamos ante una autora barroca. Ella es muy capaz de afinar su lira. Es por ello que podríamos afirmar metafóricamente que sor Juana fue una música bien temperada pero no entendiendo esta metáfora como una afirmación positiva avant la lettre, sino como una realidad cultural, estética y psíquica de nuestra autora, siempre investigando, siempre confrontando diversas fuentes y teorías no sólo en el plano de lo especulativo, sino en la materialidad fáctica de sus prácticas y juegos cotidianos, siempre tratando de saciar esa inagotable curiosidad suya que la impulsa a explorar en los antiguos y los modernos las más diversas disciplinas, como todos los grandes barrocos de su siglo.

\section{BibLIOGRAFÍA}

Agustín de Hipona, san. La ciudad de Dios. Introducción de Francisco Montes de Oca. México: Editorial Porrúa, 17a. ed., 2004 ("Sepan cuántos...", 59).

Cerone, Pietro. El Melopeo y Maestro. Tratado de musica theorica y practica. Nápoles: Juan Bautista Gareno y Lucrecio Nucci, 1613; El Melopeo y Maestro. Ed. de Antonio Ezquerro Esteban, 2 vols., Madrid: Consejo Superior de Investigaciones Científicas, 2007 (Monumentos de la Música Espańola, 74).

Corripio Rivero, Manuel. "Sor Juana y la música", en Ábside, México, 1962, vol. XXVI, núm 4: 436-484; 1963, vol. XXVII, núm. 2: 174195; 1963, vol. XXVII, núm. 4: 479-496; 1964, vol. XXVIII, núm. 1: 90-101.

Cruz, san Juan de la. Obras del Mistico Doctor. Edición crítica, vol. 2. Introducción y notas de P. Gerardo de San Juan de la Cruz. Epílogo de Juan Vázquez de Mella. Toledo: Viuda e Hijos de J. Peláez, 1912.

Cruz, SOR JuANa INés De LA. Obras completas, 4 vols., vols. I, II y III, edición, prólogo y notas de Alfonso Méndez Plancarte; vol. IV, prólogo y notas de Alberto G. Salceda. México: Fondo de Cultura Económica, 1976.

Deleuze, Gilles. El pliegue. Traducción de José Vázquez y Umbelina Larraceleta. Barcelona / Buenos Aires: Paidós, 1989.

Ficino, Marsilio. Sententiae pulcherrimae cum multarum rerum definitionibus: ex Marsilii Ficini Florentini, Philosophi Platonici, Medici, \& Theologi clarissimi operibus collectae. Basileae: Adamum Henricum Petri, 1576. 
Ficino, Marsilio. "Commentarium in Timaeum", en Opera. Tomus Secundus. Parisiis: Guillelmum Pelé, 1641.

Ficino, Marsilio. Tres libros sobre la vida (Luigi Cornaro, De la vida sobria). Traducción de Marciano Villanueva Salas. Madrid: Asociación Española de Neuropsiquiatría, 2006.

Gaffurio, Franchino. Theorica music[a]e. Ioannis Petri de Lomatio, 1492.

Gaffurio, Franchino. Practica musicae. Milan, 1496.

Gil, LuIs. Therapeia. La medicina popular en el mundo clásico. Madrid: Guadarrama, 1969 (Crítica y Ensayo, 50).

Haar, James. "The Frontispiece of Gaffori's Practica Musicae". Renaissance Quarterly, 27,1, Spring, 1974: 7-22.

Hernando González, Alfonso. "Francisco Salinas (1513-1590): la teoría musical en la encrucijada entre lo antiguo y lo moderno", en Historia de las ciencias y de las técnicas, vol. 2. Logroño: Universidad de la Rioja, 2004: 961-975.

Jámblico. Sobre los misterios egipcios. Introducción, traducción y notas de Enrique Ángel Ramos Jurado. Madrid: Editorial Gredos, 1997.

Lavista, Mario. "Notas sin música”, en Pauta. Teoría y crítica músical, 1983, 2, 6: 94-97.

Leonard, Irving. Los libros del conquistador. México: Fondo de Cultura Económica, 1953.

Lida, Raymundo. "Sor Juana y el regateo de Abraham”, en Actas del Sexto Congreso Internacional de Hispanistas, celebrado en Toronto, 1977. Edición de Alan M. Gordon. Toronto: University of Toronto, 1980: 455-458.

Long, Pamela H. "El Caracol". Music in the works of SJIC. Ann Arbor: U.M.I., 1992 (Tesis doctoral, Tulane University, 1990); Sor Juana/Música: How the Décima Musa Composed, Practiced, and Imagined Music. New York: Peter Lang, 2009 (Iberica, 39).

Mazzeo, Joseph Anthony. "St. Augustine's Rhetoric of Silence", en Journal of the History of Ideas, 23, 2, abr-jun, 1962: 175-196.

Menéndez Pelayo, Marcelino. Historia de los heterodoxos españoles. Libro Quinto, Epílogo, V. Madrid: La Editorial Católica, 1978.

Nieremberg, Juan Eusebio. Curiosa filosofia y qvestiones natvrales y Oculta filosofia, en Obras filosoficas. Ethicas, politicas y fisicas, que contienen lo principal de la Filosofia Moral, Ciuil y Natural, todo conforme a la piedad Christiana. Tomo tercero. Corregidas y enmendadas en esta ultima impression. Sevilla: Lucas Martin de Hermosilla, 1686.

Olivares Zorrilla, Rocío. "Refracción e imagen emblemática en el Primero sueño, de Sor Juana”, en Studi Latinoamericani / Estudios Latinoamericanos, 4, Universitá di Udine, 2008: 251-282. En línea, <http://bib. cervantesvirtual.com/FichaObra.html? Ref=35907 >. 
Olivares Zorrilla, Rocío. “Juan Eusebio Nieremberg y Sor Juana Inés de la Cruz", en Doctrina y diversión en la cultura española y novohispana. Edición de Ignacio Arellano y Robin Rice. Madrid: Iberoamericana, 2009: 149-165.

Olivares Zorrilla, Rocío. La figura del mundo en "El sueño", de Sor Juana Inés de la Cruz. Ojo y "spiritus phantasticus" en un sueño barroco. Madrid: Editorial Académica Española, 2012.

Ortiz, Mario. “La Musa y el Melopeo", en Hispanic Review, Summer, 2007: 253-264.

Pascual Buxó, José. Sor Juana Inés de la Cruz: lectura barroca de la poesía. Sevilla: Renacimiento, 2006 (Otros Títulos, 59).

Paz, Octavio. Sor Juana Inés de la Cruz o las trampas de la fe, 2a. ed. México: Fondo de Cultura Económica, 1983.

Pérez de Soto, Melchor. Documentos para la historia de la cultura en México. Una biblioteca del siglo XVII. México: Publicaciones del Archivo General de la Nación, 1947.

Ramos de Pareja, Bartolomé. Musica practica. Bononiae: Baltasaris de Hiriberia, 1482.

Ramos de Pareja, Bartolomé. Música práctica. Traducción de José Luis Moralejo. Introducción de Enrique Sánchez Pedrote. Madrid: Alpuerto, 1983.

Salinas, Francisco. Siete libros sobre la música. Traducción de Ismael Fernández de la Cuesta. Madrid: Alpuerto, 1986 (Opera omnia).

Sigüenza y Góngora, Carlos de. "Libra astronómica y filosófica”, en Seis obras. Prólogo de Irving A. Leonard, edición, notas y cronología de William G. Bryant. Caracas: Biblioteca Ayacucho, 1984: 243-409.

Sinesio de Cirene. "De insomniis", en Patriologiae. Cursus completus, t. LXVI. Paris: Migne Editorem, 1859: 1281-1320.

Soriano Vallés, Alejandro. El "Primero sueño" de Sor Juana Inés de la Cruz. Bases tomistas. México: Universidad Nacional Autónoma de México / Instituto de Investigaciones Estéticas, 2000 (Estudios de Literatura, 6).

Tomlinson, Gary. Music in Renaissance Magic. Toward a Historiography of Others. Chicago / London: University of Chicago Press, 1993.

Trabulse, Elías. El círculo roto. México: Fondo de Cultura Económica / Secretaría de Educación Pública, 1984 (Lecturas Mexicanas, 54).

Vico, Giambattista. Principi di Scienza Nuova d'intorno alla comune natura delle nazione, tomo I. Napoli: Stamperia Muziana, 1744.

Voss, Angela. "The Music of the Spheres; Marsilio Ficino and Renaissance Harmonia", en Culture and Cosmos. A Journal of the History of Astrology and Cultural Astronomy, 2, 2, 1998: 16-38. 
Vossler, Carlos. "La Décima Musa de México, SJIC", en Escritores y poetas de España. Traducción de Carlos Clavería. Buenos Aires / México: Espasa-Calpe, 2a. ed., 1948 (Austral, 771): 103-129.

Zarlino da Chioggia, Gioseffo. Le Istitutioni Harmoniche. Venetia, 1558. 